\title{
KEEPING THE NAMES STRAIGHT
}

\author{
FIRST GENERATION
}

Migdim: the old mother

Jawwad: Migdim's husband, deceased

\section{SECOND GENERATION}

Hamid: Migdim's eldest son

Sagr: $\quad$ (or Haj Sagr) Migdim's second son

Dhahab: Migdim's eldest daughter

Ngawa: Migdim's second daughter

Lawz: Migdim's youngest daughter

Gateefa: Sagr's senior wife and first cousin

Safiyya: Sagr's second wife

Azza: Sagr's third wife

Fayga: wife of one of Migdim's other sons

\section{THIRD GENERATION}

Sabra: eldest daughter of Gateefa and Sagr

Kamla: $\quad$ second daughter of Gateefa and Sagr

Selima: Hamid's daughter

Aisha: family friend and Kamla's future sister-in-law

Khwayyir: Migdim's grandson

Salih: $\quad$ Migdim's grandson

\section{FOURTH GENERATION}

Kafy: $\quad$ Migdim's great-grandson, grandson of Sagr and Safiyya 


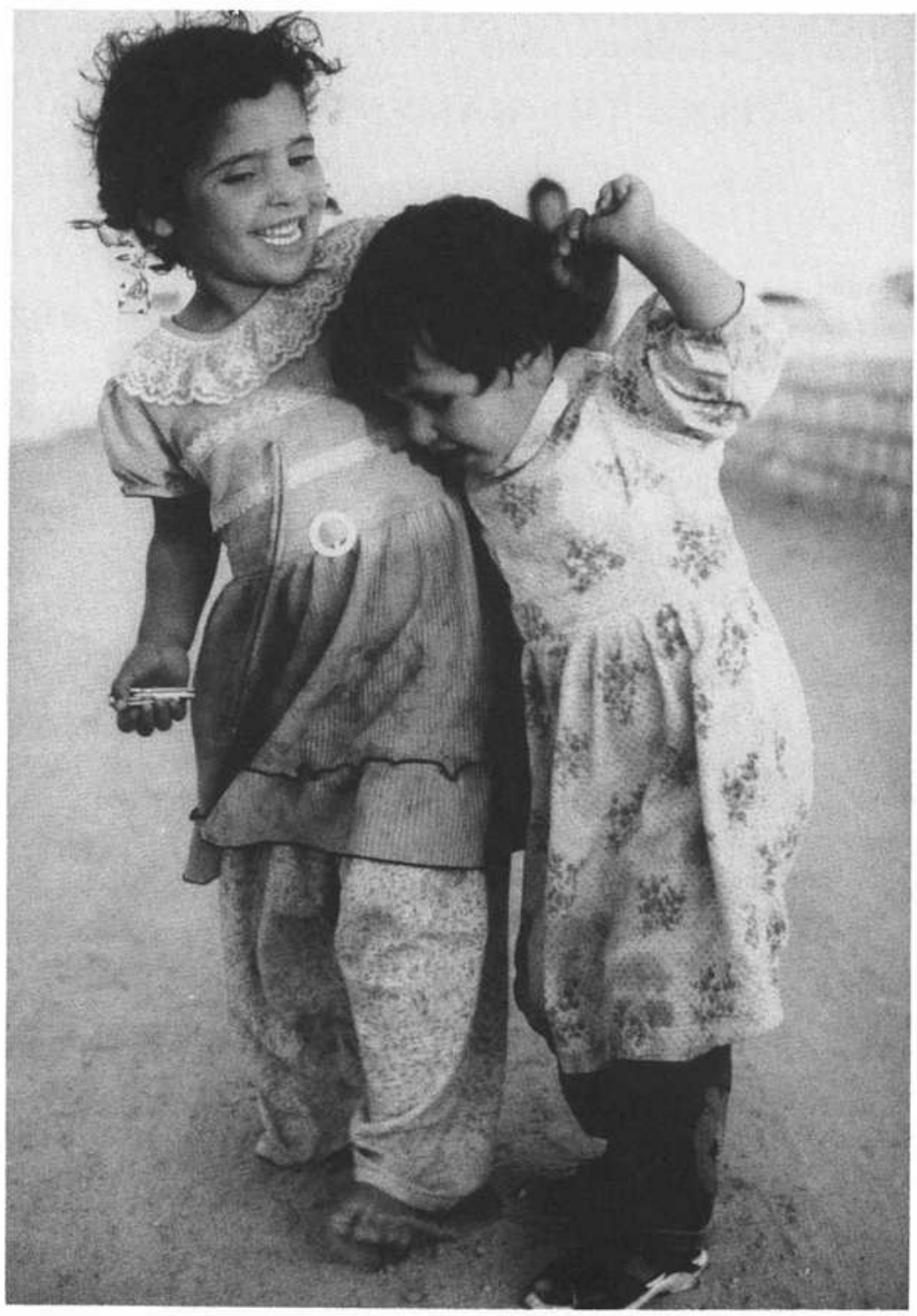

